\title{
Estimation of Surabaya River Water Quality Using Kalman Filter Algorithm
}

\author{
Ali Masduqi ${ }^{1}$ dan Erna Apriliani ${ }^{2}$
}

\begin{abstract}
According to previous studies on Surabaya River water, quality of this river water was very bad or on polluted condition. This conclusion was based on monitoring data of water quality at several monitoring points. Because of river water quality is a fluctuative condition, many monitoring data are needed. While, monitoring of Surabaya River water quality was done routinely at nine monitoring points. Amount of the monitoring point is not enough when data will be used for determining water quality condition. For this reason, it is need to develop a method to estimate overall river water quality based on a little amount of data. One of estimation method is Kalman filter, an algorithm that combines a model and a measurement. The experiment of Kalman filter algorithm was conducted. The results were accurate and closely with a measurement. Based on the results, application of Kalman filter algorithm will help to predict water quality for the future and to estimate overall water quality along of river, although amount of measurement data is a little.
\end{abstract}

Keywords-Surabaya River, Estimation, Prediction, Kalman filter

\section{Pendahuluan}

K ali Surabaya memiliki arti penting bagi Kota Surabaya. Kali Surabaya menjadi sumber utama bagi PDAM Surabaya dan beberapa industri di sepanjang Kali Surabaya. Fungsi penting ini menjadi salah satu alasan pentingnya menjaga air Kali Surabaya dari pencemaran.

Beberapa studi yang dilakukan pada air Kali Surabaya selama tujuh tahun terakhir menunjukkan kualitas air Kali Surabaya masih belum memenuhi persyaratan sebagai air baku bagi instalasi penjernihan air minum. Laporan penelitian [1] menunjukkan bahwa terdapat 483 industri di sepanjang Sungai Brantas yang membuang limbahnya dan menjadi sumber utama pencemaran air Kali Surabaya. Beban pencemaran diperkirakan sebesar 125 ton BOD/hari. Sebanyak $96 \%$ dari beban ini berasal dari 45 industri yang potensi cemarnya sangat berat.

Studi kualitas lingkungan hidup di Jawa Timur yang dilakukan Bapedal dan Lembaga Penelitian ITS [2] menyatakan bahwa pencemaran yang berat terjadi pada bagian hilir Kali Surabaya yang disebabkan oleh limbah industri dan limbah domestik di daerah padat penduduk. Selanjutnya studi oleh PDAM dan Jurusan Teknik Lingkungan ITS [3] merekomendasikan agar Pemerintah Provinsi Jawa Timur berusaha menekan pencemaran Ka-

Naskah diterima 21 Februari 2007; selesai revisi pada 15 Mei 2008

${ }^{1}$ Ali M. adalah dosen Jurusan Teknik Lingkungan, FTSP, Institut Teknologi Sepuluh Nopember, Surabaya, INDONESIA (e-mail: masduqi@its.ac.id)

2 Erna A. adalah dosen Jurusan Matematika, FMIPA, Institut Teknologi Sepuluh Nopember, Surabaya, INDONESIA li Surabaya secara serius dan agar Pemerintah Kota Surabaya mencari sumber air baku untuk PDAM yang kualitasnya lebih layak.

Pada studi pemetaan industri berpotensi cemar yang dilakukan Dinas Perindustrian dan Perdagangan Provinsi Jawa Timur dan Jurusan Teknik Lingkungan ITS [4] diperoleh hasil bahwa pencemaran air Kali Surabaya terjadi sejak kilometer ke-24 (dari Dam Jagir) dan yang tertinggi adalah setelah ada masukan aliran dari Kali Tengah.

East Java Regional Sector Development and Reform Program (EJRSDRP), Project World Bank [5] untuk pengumpulan data kualitas air Kali Surabaya menemukan minimnya data yang dikumpulkan oleh instansi pengelola Kali Surabaya. Pada Kali Surabaya yang panjangnya sekitar $42 \mathrm{~km}$ (dari Dam Mlirip hingga Dam Jagir), Perum Jasa Tirta I hanya memantau kualitas air Kali Surabaya di sembilan stasiun monitoring.

Jumlah sampel dari sembilan titik ini dirasa masih kurang bisa mewakili kondisi Kali Surabaya. Karena itu perlu dikembangkan suatu metoda untuk mengestimasi kondisi kualitas air Kali Surabaya pada ruas yang tidak terdapat stasiun monitoring. Salah satu metoda estimasi yang cukup akurat adalah algoritma filter Kalman. Tulisan ini akan memberikan gambaran tentang penerapan algoritma filter Kalman untuk estimasi kualitas air Kali Surabaya.

\section{FILTER KALMAN}

Filter Kalman adalah suatu pendekatan teknis menaksir fungsi parameter dalam peramalan deret berkala (time series). Keunggulan filter Kalman adalah kemampuan mengestimasi suatu keadaan berdasarkan data yang minim. Filter Kalman merupakan suatu algoritma yang menggabungkan model dan pengukuran. Data pengukuran terbaru menjadi bagian penting dari algoritma filter Kalman karena data mutakhir akan mengoreksi hasil prediksi, sehingga hasil estimasi selalu mendekati kondisi yang sebenarnya.

Persamaan dasar yang digunakan dalam estimasi adalah persamaan linier untuk continuous-time Kalman filter sebagai berikut [6]:

$\dot{x}(t)=F(t) x(t)+G(t) w(t)$

dengan kondisi awal $x(t)=x_{0}$.

Keterangan:

$x(t)=$ state vector berdimensi $n \times 1$, yang menyatakan error model state

$F(t)=$ matriks $n x n$, yang menyatakan dinamika model sistem dan error

$G(t)=$ matriks $n x r$, disebut juga noise gain matrix yang menyatakan pengaruh dinamika input 
$w(t) \quad=$ vektor input stokastik berdimensi $r \times 1$

Persamaan model estimasi tersebut didukung dengan persamaan yang menyatakan data pengukuran sebanyak $m$ buah, yaitu:

$z(t)=H(t) x(t)+v(t)$

dengan:

$z(t)=$ vector berdimensi $m \times 1$, vektor pengukuran atau output

$H(t) \quad=$ matriks $m \times n$, disebut juga matriks pengukuran atau observasi

$v(t) \quad=$ vector error observasi stokastik berdimensi $m x 1$

Dalam prakteknya, algoritma filter Kalman diimplementasikan dalam komputer digital yang hanya menerima data diskret atau data sequence. Model discrete-time Kalman filter serupa dengan model continuous-time Kalman filter yang menggunakan pendekatan forward $\mathrm{Eu}$ ler.

Langkah-langkah algoritma discrete-time Kalman filter meliputi:
a. State prediction
b. Observation prediction
c. Innovations
d. Covariance prediction
e. Innovation covariance
f. Kalman gain
g. State update
h. Covariance update

Langkah-langkah di atas dapat digambarkan dengan diagram alir seperti pada Gambar 1.

Algoritma filter Kalman telah banyak diaplikasikan pada pemodelan hidrologi [7], seperti pemodelan air tanah, limpasan hujan, air permukaan dan sebagainya. Referensi [8] menggunakan filter Kalman ensemble untuk estimasi model hidrologi, yaitu model aliran air tanah, kelembaban tanah, presipitasi, dan aliran sungai.

\section{ALIRAN AIR SUNGAI}

\section{A. Model Penyebaran Polutan}

Kualitas air dapat dinyatakan dengan parameter BOD (biochemical oxygen demand) yang menyatakan besarnya kebutuhan oksigen untuk menguraikan bahan organik yang mencemari air sungai. Perhitungan BOD dalam sistem sungai dapat didekati dengan model plug flow [9] dengan volume kontrol pada Gambar 1.

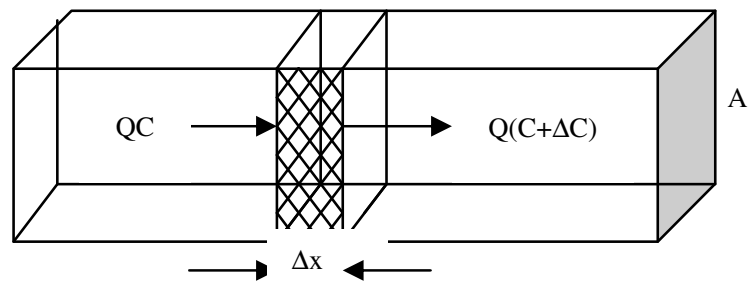

Gambar 1. Volume kontrol aliran sistem plug flow [9]

Perhitungan volume kontrol adalah sebagai berikut: Accumulation $=$ Inputs - Outputs + Reactions $\frac{d(V C)}{d t}=Q C-Q(C+\Delta C)-k C V$
$C \frac{d V}{d t}+V \frac{d C}{d t}=Q C-Q(C+\Delta C)-k C V$

Persamaan (2) dibagi dengan $\mathrm{V}$, untuk $\mathrm{V}=\mathrm{A} . \Delta \mathrm{x}$ dan $\mathrm{dV} / \mathrm{dt}=0$, maka:

$\frac{d C}{d t}=\frac{Q C}{A \Delta x}-\frac{Q C}{A \Delta x}-\frac{Q \Delta C}{A \Delta x}-k C$

Untuk limit $\Delta \mathrm{x} \rightarrow 0$, maka:

$\frac{\partial C}{\partial t}=-\frac{Q \partial C}{A \partial x}-k C$

Bila $Q / A=\bar{u}$, maka:

$\frac{\partial C}{\partial t}=-\bar{u} \frac{\partial C}{\partial x}-k C$

dengan:

$Q \quad=$ debit sungai

C = konsentrasi polutan

$V \quad=$ volume

$A \quad=$ luas penampang

$t \quad=$ waktu

$k \quad=$ konstanta reaksi biodegradasi

$\bar{u} \quad=$ kecepatan aliran air

$x \quad=$ panjang segmen sungai

\section{B. Data Fisik dan Pengukuran}

Kali Surabaya melintasi Kota/Kabupaten Mojokerto, Kabupaten Sidoarjo, Kabupaten Gresik, dan Kota Surabaya, yang panjangnya sekitar $42 \mathrm{~km}$ mulai dari Dam Mlirip hingga Dam Jagir. Lebar sungai bervariasi 60 hingga 100 meter. Debit di Dam Mlirip bervariasi 7 hingga $70 \mathrm{~m}^{3} /$ detik (data Perum Jasa Tirta Januari 1991 hingga Desember 2003).

Di sepanjang Kali surabaya terdapat sembilan stasiun pemantauan kualitas air, yaitu Canggu, Perning, Jrebeng, Cangkir, Bambe, Karangpilang, Sepanjang, Gunungsari, dan Jagir. Lokasi sembilan stasiun dapat dilihat pada Gambar 3. Pada sembilan stasiun tersebut, Perum Jasa Tirta I selalu melakukan pemantauan kualitas secara rutin tiap bulan, kecuali di Karangpilang dan Jagir yang dipantau tiap minggu. Parameter kualitas air yang dipantau meliputi keasaman $(\mathrm{pH})$, kadar oksigen terlarut (DO), kebutuhan oksigen secara biokimia (BOD), kebutuhan oksigen secara kimiawi (COD), padatan tersuspensi (TSS), kadar nitrat, dan kadar fosfat.

Pada aplikasi filter Kalman untuk estimasi kualitas air Kali Surabaya ini digunakan data BOD hasil monitoring bulanan pada bulan Januari 1998 sampai Desember 2002 di sembilan stasiun monitoring.

\section{Estimasi DENGAN FILTER KALMAN}

Estimasi kualitas air sungai diawali dengan pendiskretan persamaan model penyebaran polutan (pers. 7) sebagai berikut:

$$
\begin{aligned}
& \frac{C_{t+1}^{j}-C_{t}^{j}}{\Delta t}=-\bar{u}\left(\frac{C_{t}^{j}-C_{t}^{j-1}}{\Delta x}\right)-k C_{t}^{j} \\
& C_{t+1}^{j}=-\bar{u} \Delta t\left(\frac{C_{t}^{j}-C_{t}^{j-1}}{\Delta x}\right)-k \Delta t C_{t}{ }^{j}+C_{t}{ }^{j} \\
& C_{t+1}^{j}=\left(-\frac{\bar{u} \Delta t}{\Delta x}-k \Delta t+1\right) C_{t}{ }^{j}+\frac{\bar{u} \Delta t}{\Delta x} C_{t}^{j-1}
\end{aligned}
$$

Bila $\bar{u}=\Delta x / \Delta t$, maka: 


$$
C_{t+1}^{j}=-k \frac{\Delta x}{\bar{u}} C_{t}^{j}+C_{t}^{j-1}
$$

dengan:

$j=$ segmen sepanjang Kali Surabaya

Pada estimasi ini, Kali Surabaya dibagi menjadi 42 segmen (masing-masing $1 \mathrm{~km}$ ), sehingga $\mathrm{j}=1,2,3, \ldots \ldots$. 42 (dari Mlirip ke Jagir). Dengan asumsi $k=0,40 /$ hari (sama sepanjang sungai) dan $\bar{u}=0,4 \mathrm{~m} /$ detik (sama sepanjang sungai), BOD sepanjang Kali Surabaya (42 titik) pada bulan tertentu dapat diprediksi. Pada saat data bulan berikutnya diperoleh, data ini digunakan untuk koreksi prediksi. Selanjutnya hasil koreksi ini digunakan kembali untuk prediksi pada bulan berikutnya, demikian seterusnya.

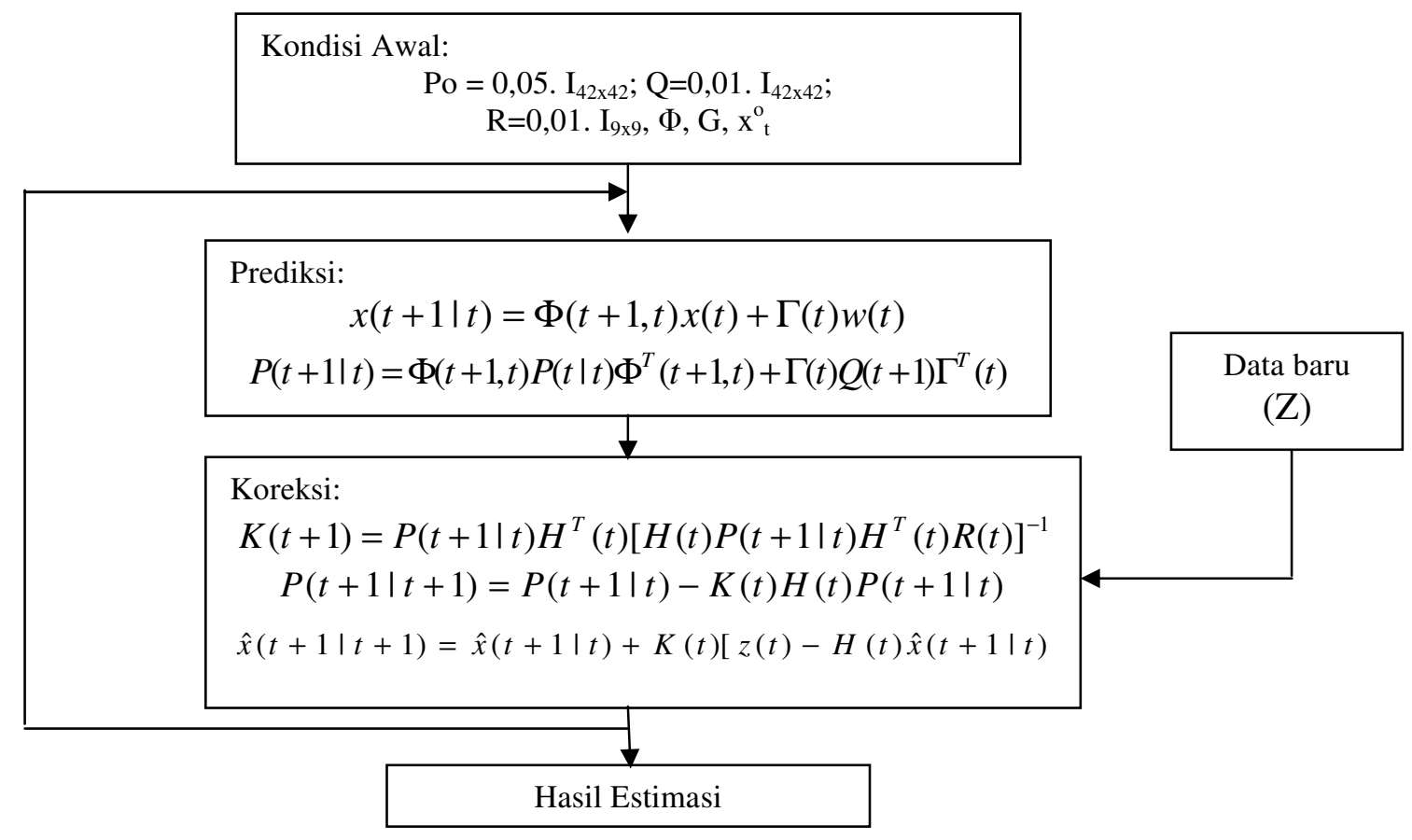

Keterangan notasi:

Gambar 2. Algoritma Filter Kalman (dimodifikasi dari referensi [6])

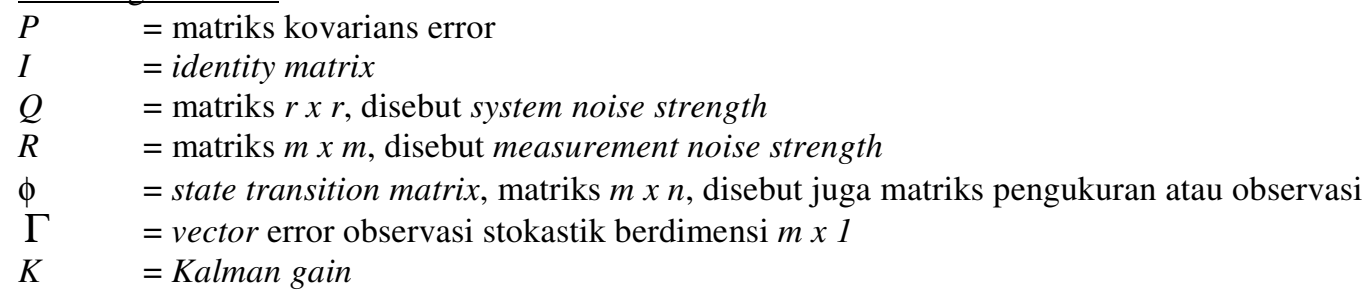

Program komputer yang digunakan untuk perhitungan adalah MATLAB 7.0. Hasil yang diperoleh adalah prediksi nilai BOD sebanyak 42 titik di sepanjang Kali Surabaya untuk satu bulan yang akan datang (X1). Hasil prediksi ini dikoreksi dengan memasukkan data pengukuran terbaru $(Z)$, sehingga akan mengubah nilai matriks covariance $(P)$ dan Kalman gain $(K)$. Nilai $P$ dan $K$ yang baru ini digunakan untuk menghitung nilai BOD sebanyak 42 titik di sepanjang Kali Surabaya untuk satu bulan sedang berjalan. Ini adalah hasil estimasi. Nilai ini digunakan lagi untuk memprediksi kondisi pada bulan depannya lagi, demikian seterusnya.

Sebagai aplikasi, pada perhitungan ini digunakan data bulanan selama 60 bulan. Setelah melalui iterasi $60 \mathrm{kali}$, diperoleh hasil estimasi:

$\hat{x}(t+1 \mid t+1)=\hat{x}(t+1 \mid t)+K(t)[z(t)-H(t) \hat{x}(t+1 \mid t) \mathrm{H}$ asil estimasi diplot pada grafik dan sebagai perbandingan ditampilkan grafik dari data BOD pada bulan yang ber- sangkutan (Gambar 4, 5 dan 6). Hasil estimasi ini mempunyai nilai dan pola yang cenderung mendekati sama dengan hasil pengamatan pada titik-titik pengamatan. Hasil ini juga dapat mengestimasi BOD pada titik-titik yang tidak terdapat data pengamatan.

Pada perhitungan ini juga diperoleh matriks covariance of error,

$$
P(t+1 \mid t+1)=P(t+1 \mid t)-K(t) H(t) P(t+1 \mid t)
$$

berukuran $42 \times 42$. Nilai matriks ini sangat kecil (mendekati nol) dengan nilai elemen diagonal matriks seperti tertera pada Tabel 1. Matriks covariance of error menyatakan kovarians perbedaan antara true state vector $\mathbf{x}(t)$ dan estimated state vector $\hat{x}(t)$ [6].

Berdasarkan hasil estimasi dan perhitungan covariance of error, dapat dilihat bahwa metoda filter Kalman mampu mengestimasi kualitas air Kali Surabaya dengan cukup akurat. Aplikasi algoritma filter Kalman 


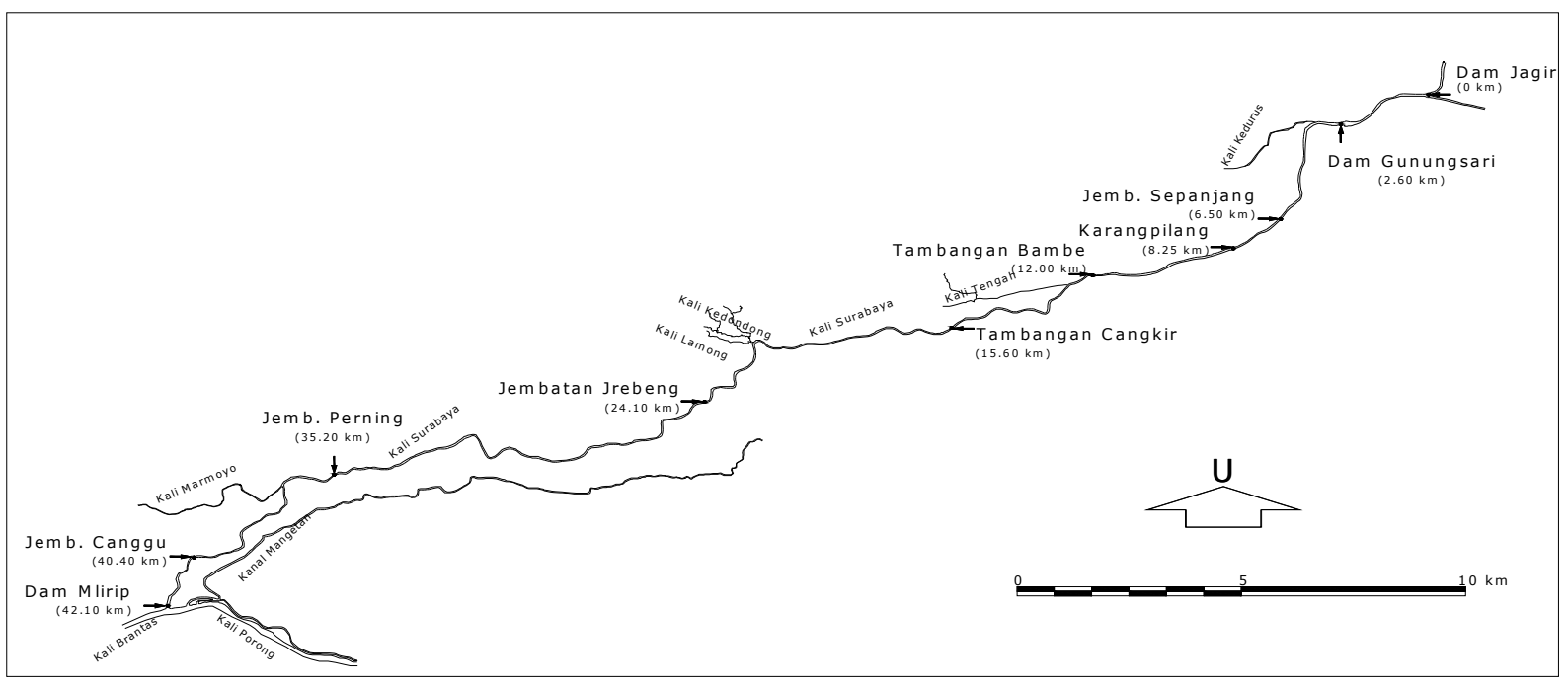

Gambar 3. Lokasi sampling kualitas air Kali Surabaya (World Bank, 2004)

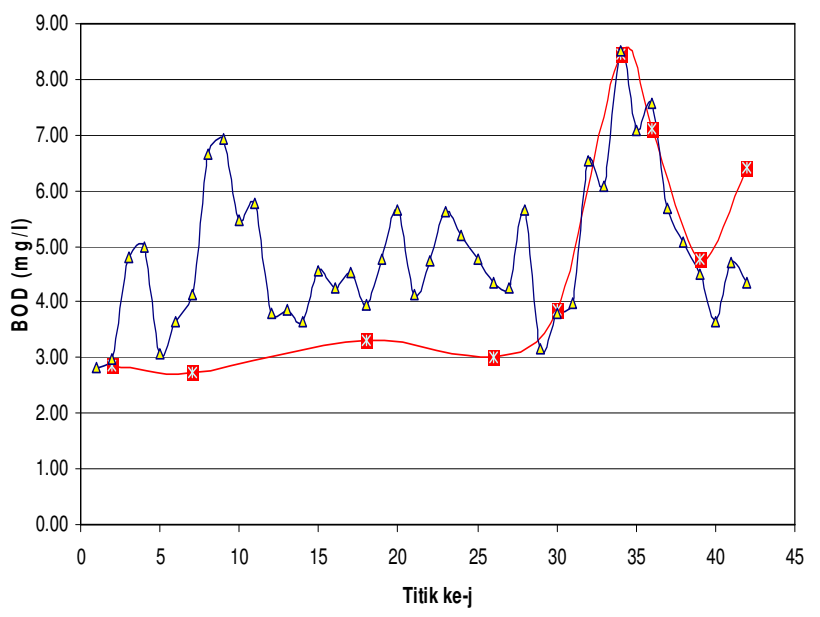

$-\mathbb{W}$-Data Okt. $2002 \quad \triangle-$ Estimasi

Gambar 4. Hasil estimasi berdasarkan data selama 58 bulan dibandingkan data Bulan Oktober 2002

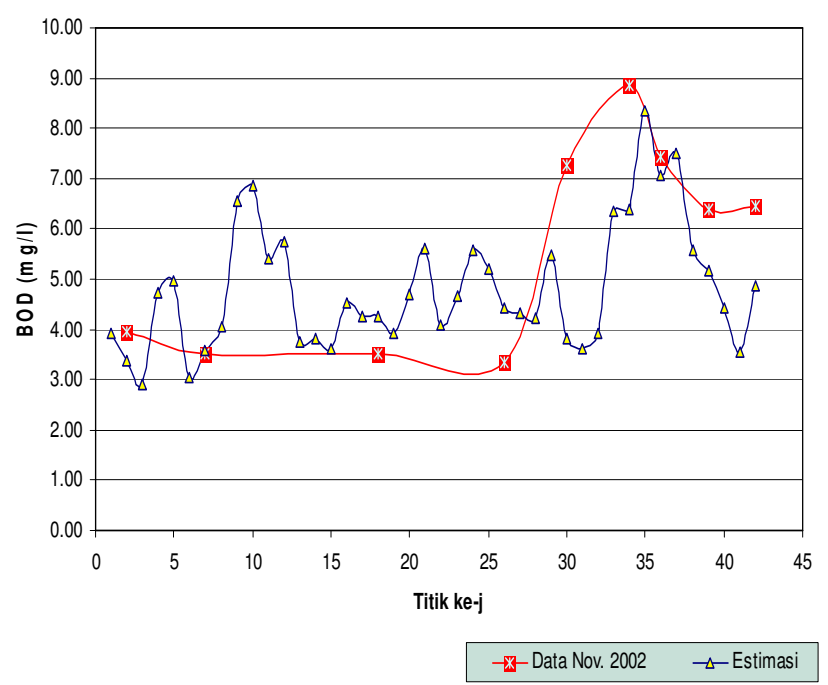

Gambar 5. Hasil estimasi berdasarkan data selama 59 bulan dibandingkan data Bulan November 2002

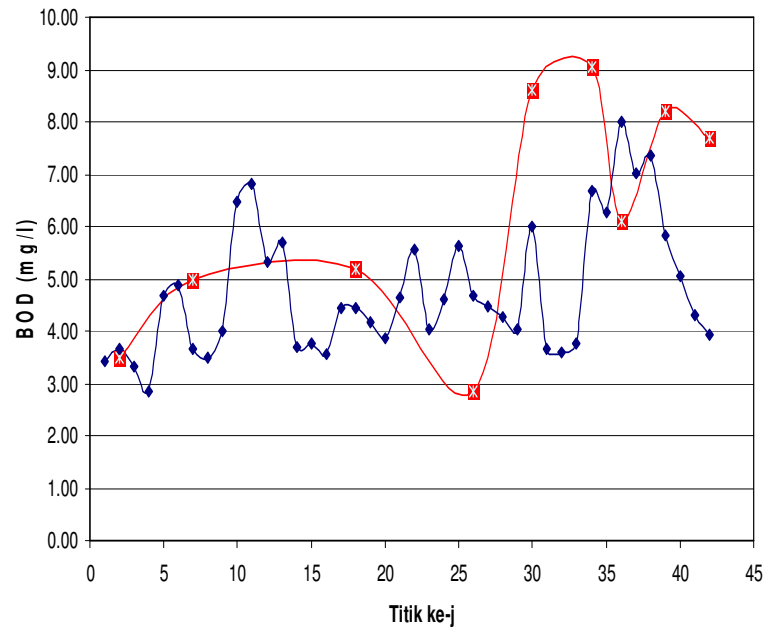

$\rightarrow$ * Data Des. $2002 \quad \rightarrow-$ Estimas

Gambar 6. Hasil estimasi berdasarkan data selama 60 bulan dibandingkan data Bulan Desember 2002

pada pengelolaan air sungai akan sangat membantu dalam memprediksi kualitas untuk waktu ke depan dan mengestimasi kualitas secara keseluruhan, meskipun dengan jumlah titik pengamatan yang sedikit.

Pada aplikasi ini, data yang digunakan adalah data bulanan, padahal kualitas air sungai dapat berubah setiap saat dengan sangat cepat. Karena itu hasil estimasi pun periodenya juga bulanan dan kurang mewakili periode waktu tertentu. Bila pemantauan dilakukan secara online atau real time, manfaat algoritma filter Kalman akan sangat terasa karena kualitas di segmen ke-j mempengaruhi kualitas di segmen $k e-j+1$ beberapa saat kemudian. Input data dilakukan real time dari stasiun monitoring dan hasil estimasi dapat dihitung dengan cepat oleh komputer. Dengan demikian dapat diambil tindakan dengan cepat bila terdapat kejadian pencemaran pada titik-titik tertentu. 
TABEL 1

NiLAi DiAgONAL MATRIKS COVERAGE OF ERROR

\begin{tabular}{|c|c|c|c|}
\hline $\begin{array}{c}\text { Baris dan } \\
\text { Kolom ke: }\end{array}$ & Nilai & $\begin{array}{c}\text { Baris dan } \\
\text { Kolom ke: }\end{array}$ & Nilai \\
\hline 1 & 0.0100 & 22 & 0.0026 \\
2 & 0.0050 & 23 & 0.0026 \\
3 & 0.0050 & 24 & 0.0026 \\
4 & 0.0050 & 25 & 0.0026 \\
5 & 0.0050 & 26 & 0.0021 \\
6 & 0.0050 & 27 & 0.0020 \\
7 & 0.0033 & 28 & 0.0021 \\
8 & 0.0033 & 29 & 0.0020 \\
9 & 0.0033 & 30 & 0.0017 \\
10 & 0.0034 & 31 & 0.0017 \\
11 & 0.0034 & 32 & 0.0017 \\
12 & 0.0034 & 33 & 0.0017 \\
13 & 0.0034 & 34 & 0.0015 \\
14 & 0.0034 & 35 & 0.0015 \\
15 & 0.0034 & 36 & 0.0013 \\
16 & 0.0034 & 37 & 0.0013 \\
17 & 0.0034 & 38 & 0.0013 \\
18 & 0.0025 & 39 & 0.0011 \\
19 & 0.0025 & 40 & 0.0011 \\
20 & 0.0025 & 41 & 0.0011 \\
21 & 0.0026 & 42 & 0.0010 \\
\hline
\end{tabular}

\section{KESIMPULAN}

Algoritma filter Kalman dapat diterapkan pada pengelolaan kualitas air sungai dengan hasil yang cukup akurat dan sangat mendekati nilai hasil pemantauan. Dengan penerapan metoda ini, jumlah titik pemantauan yang sedikit tidak menjadi kendala dalam menilai kondisi air sungai secara keseluruhan, sehingga tidak perlu ada penambahan jumlah stasiun monitoring. Metoda ini juga siap diterapkan bila pemantauan dilakukan secara online.

\section{DAFTAR PUSTAKA}

[1] ---------, "Surabaya River Pollution Control Action Plan Study”, Binnie \& Partners (overseas) Ltd. 1999

[2] --------, "Studi Kualitas Lingkungan Hidup di Jawa Timur", Lembaga Penelitian ITS - BAPEDAL Provinsi Jawa Timur. 2000 .

[3] -------, "Penelitian: Menuju Air Siap Minum", PDAM Surabaya dan Jurusan Teknik Lingkungan ITS. 2000

[4] ---------, "Pemetaan Industri Potensi Cemar di Jawa Timur", Dinas Perindustrian dan Perdagangan Provinsi Jawa Timur Jurusan Teknik Lingkungan ITS. 2003.

[5] ---------, "Water Quality and Resource Protection Strategy Policy Review", Volume I, Indonesia East Java Proposed East Java Regional Sector Development and Reform Program (EJRSDRP), The World Bank - PT Waseco Tirta. 2004.

[6] Siouris, G.M., An Engineering Approach to Optimal Control and Estimation Theory, John Wiley \& Sons, Inc. New York. 1996.

[7] Drécourt, JP., "Kalman filtering in hydrological modeling", DAIHM Technical Report 2003-1, DHI Water \& Environment, Agern All 11, 2970 Hørsholm, Denmark. 2003.

[8] Moradkhani, H., Sorooshian, S., Gupta, H.V., dan Houser, P.R., "Dual state-parameter estimation of hydrological models using ensemble Kalman filter", Advances in Water Resources 28, p. 135-147. 2005.

[9] Schnoor, J.L., Environmental Modeling, Fate and Transport of Pollutants in Water, Air, and Soil, John Wiley \& Sons, Inc. New York. 1996. 